\title{
The safety and efficacy of anterior versus posterior decompression surgery in degenerative cervical myelopathy: a prospective randomized trial
}

\author{
Nasser M. F. El-Ghandour, MD, Mohamed A. R. Soliman, MD, Ahmed A. M. Ezzat, MSc, \\ Amr Mohsen, MD, and Mostafa Zein-Elabedin, MD \\ Department of Neurosurgery, Faculty of Medicine, Cairo University, Cairo, Egypt
}

OBJECTIVE The safety and efficacy of anterior and posterior decompression surgery in degenerative cervical myelopathy (DCM) have not been validated in any prospective randomized trial.

METHODS In this first prospective randomized trial, the patients who had symptoms or signs of DCM were randomly assigned to undergo either anterior cervical discectomy and fusion or posterior laminectomy with or without fusion. The primary outcome measures were the change in the visual analog scale (VAS) score, Neck Disability Index (NDI), and Nurick myelopathy grade 1 year after surgery. The secondary outcome measures were intraoperative and postoperative complications, hospital stay, and Odom's criteria. The follow-up period was at least 1 year.

RESULTS A total of 68 patients (mean age $53 \pm 8.3$ years, $72.3 \%$ men) underwent prospective randomization. There was a significantly better outcome in the NDI and VAS scores in the anterior group at 1 year $(p<0.05)$. Nurick myelopathy grading showed nonsignificant improvement using the posterior approach group $(p=0.79)$. The mean operative duration was significantly longer in the anterior group $(p<0.001)$. No significant difference in postoperative complications was found, except postoperative dysphagia was significantly higher in the anterior group $(p<0.05)$. There was no significant difference in postoperative patient satisfaction (Odom's criteria) $(p=0.52)$. The mean hospital stay was significantly longer in the posterior group $(\mathrm{p}<0.001)$.

CONCLUSIONS Among patients with multilevel DCM, the anterior approach was significantly better regarding postoperative pain, NDI, and hospital stay, while the posterior approach was significantly better in terms of postoperative dysphagia and operative duration.

https://thejns.org/doi/abs/10.3171/2020.2.SPINE191272

KEYWORDS cervical spondylotic myelopathy; degenerative cervical myelopathy; anterior cervical discectomy and fusion; cervical laminectomy; lateral mass fusion

$\mathrm{D}$ EGENERATIVE cervical myelopathy (DCM) is the most common cause of dysfunction of the spinal cord in adults worldwide. ${ }^{1}$ DCM can be due to structural changes such as degenerative disc disease, ligamentum flavum hypertrophy, facet joint hypertrophy, vertebral body osteophytes, and ossification of the posterior longitudinal ligament (OPLL) that cause spinal cord compression. It can also be due to increased mobility of the vertebrae injuring the spinal cord or abnormal spinal alignment causing spinal cord tension. ${ }^{2}$ All of these causes lead to ischemia, endothelial cell impairment, neuroinflamma- tion, spinal cord-blood barrier disruption, and neuronal and oligodendrocyte apoptosis. All of these pathophysiological consequences of compression will lead to irreversible nerve cell damage and subsequent neurological impairment. ${ }^{3}$

Patients with DCM can present with radicular symptoms as well as symptoms and signs of neurological dysfunction. Common symptoms are decreased hand dexterity, paresthesia, weakness of the upper and lower extremities, gait impairment, and Lhermitte's sign. ${ }^{1}$

There are many retrospective studies, systematic re-

ABBREVIATIONS ACDF = anterior cervical discectomy and fusion; $\mathrm{DCM}=$ degenerative cervical myelopathy; NDI = Neck Disability Index; OPLL = ossification of the posterior longitudinal ligament; VAS = visual analog scale.

SUBMITTED October 24, 2019. ACCEPTED February 27, 2020.

INCLUDE WHEN CITING Published online May 1, 2020; DOI: 10.3171/2020.2.SPINE191272. 
views, and meta-analyses that compare anterior and posterior approaches in the treatment of multilevel DCM in terms of complication rate and/or patient-reported outcomes. ${ }^{4,5}$ However, there is still no strong evidence whether multilevel DCM is best managed via an anterior or posterior approach, and because of this uncertainty, there is a substantive need for several prospective randomized trials. This is the first prospective randomized trial that compares anterior and posterior approaches to determine which procedure is superior in the management of DCM regarding effectiveness and safety.

\section{Methods \\ Study Design}

In this prospective randomized study, patients who had DCM were assigned randomly in a 1:1 ratio to undergo either anterior cervical discectomy and fusion (ACDF) or cervical laminectomy with or without fusion. We enrolled patients older than 30 years of age who were diagnosed with DCM and met the inclusion criteria (Table 1). Patients were assessed for DCM before they were randomized. Patient assessment was conducted by a neurosurgical specialist in the form of history taking, complete clinical examination, and radiological workup (dynamic radiographic views and MRI of the cervical spine). The DCM diagnosis was based on the presence of signs and symptoms of myelopathy as well as the MRI findings of a stenotic segment at two or more cervical vertebral levels.

The randomization procedure, potential surgical approaches, and required follow-up evaluations and imaging were explained in detail by the neurosurgical specialist to the potential study candidates. Upon agreement of the candidate to participate, informed consent was signed, and the candidate was randomized to one of the two surgical approaches. The procedure selection was performed by the study coordinator using a sealed envelope. In patients who were randomized to the posterior approach, fusion was added if there were any signs of instability (i.e., radiographic dynamic views showed a cervical angulation $>$ $20^{\circ}$, subluxation $>3.5 \mathrm{~mm}$, or a motion $>1-2 \mathrm{~mm}$ between the adjacent spinous process $\left.\operatorname{tips}^{6}\right)$, loss of the lordotic curve $\left(<10^{\circ}\right.$ lordotic curvature $\left.{ }^{6}\right)$, or kyphotic deformity, and the decision was made by two senior spine professors with the assistance of a radiology consultant.

\section{Data Collection and Outcomes}

We used patient-reported questionnaires including the visual analog scale (VAS) for neck pain, Neck Disability Index (NDI), and Nurick myelopathy grade to assess outcomes in this study. The questionnaires were completed preoperatively upon admission and were completed postoperatively in the outpatient clinic without the assistance of any person involved in the study.

The primary outcome measures were the scores on the NDI (range 0-50), VAS (range 0-10), and Nurick myelopathy grading scale (grade range $0-5$ ). The secondary outcome measures were intraoperative complications (dural tear and vascular injury); postoperative complications (hematoma, infection, neurological deficit, dysphagia, hoarseness of voice, and mortality); operative duration; fu-
TABLE 1. Inclusion and exclusion criteria

\begin{tabular}{l}
\hline Inclusion criteria \\
\hline Age $>30$ yrs \\
\hline $\mathrm{DCM}$ caused by multisegmental spinal stenosis ( $\geq 2$ segments) on \\
MRI \\
\hline Symptoms \& signs of myelopathy (at least 1 symptom \& 1 positive \\
physical examination finding) \\
\hline Two senior spine professors (from different training schools) agreed \\
that the case is debatable to be approached anteriorly or posteriorly \\
\hline Medically fit for surgery \\
\hline Compliance of the patient w/ the required follow-up \\
\hline Exclusion criteria \\
\hline DCM caused by single-segment spinal stenosis \\
\hline Cases undergoing combined anterior \& posterior approaches \\
\hline History of previous cervical operations \\
\hline Medically unfit for surgery \\
\hline Associated OPLL \\
\hline Lesions extending posteriorly to the vertebral body requiring \\
corpectomy
\end{tabular}

sion rate (radiographic evidence [cervical spine dynamic radiographic views] of complete bone union at the interface between the bone and graft; trabeculation progression at the interface between bone and graft without signs of graft lytic lesions; the trabeculae continuity; bridging bone, especially at the facet joints in the posterior fusion group; absence of halo or lucency surrounding the graft; and gross bony trabeculation reported by a radiology consultant as well as reviewed by a neurosurgery professor); hospital length of stay; Odom's criteria (patient satisfaction with the outcome using a scale of excellent, good, fair, and poor); and reoperation rate.

Patients were followed up in the outpatient clinic at 2 weeks, 3 months, 6 months, 9 months, and 1 year. Plain radiographs were performed within 72 hours from surgery and every 3 months for a year. Close observation of the enrolled patients was performed by the study coordinator, and the above follow-up information was immediately placed in a Microsoft Excel spreadsheet once it was recorded.

\section{Interventions}

All patients underwent either ACDF (anterior decompression group) or posterior laminectomy with or without fusion (posterior decompression group). Anterior decompression was performed through anterior cervical discectomy, posterior longitudinal ligament excision, and foraminotomy, followed by polyetheretherketone cage interbody fusion (a titanium plate was added in 4- and 5-level ACDFs only). Patients in the posterior decompression group underwent a cervical laminectomy with or without lateral mass titanium screws and rods across the stenotic levels, with a harvested bone graft from the removed lamina. All surgeons involved in the trial routinely perform both approaches.

This trial was approved by the local ethical committee 


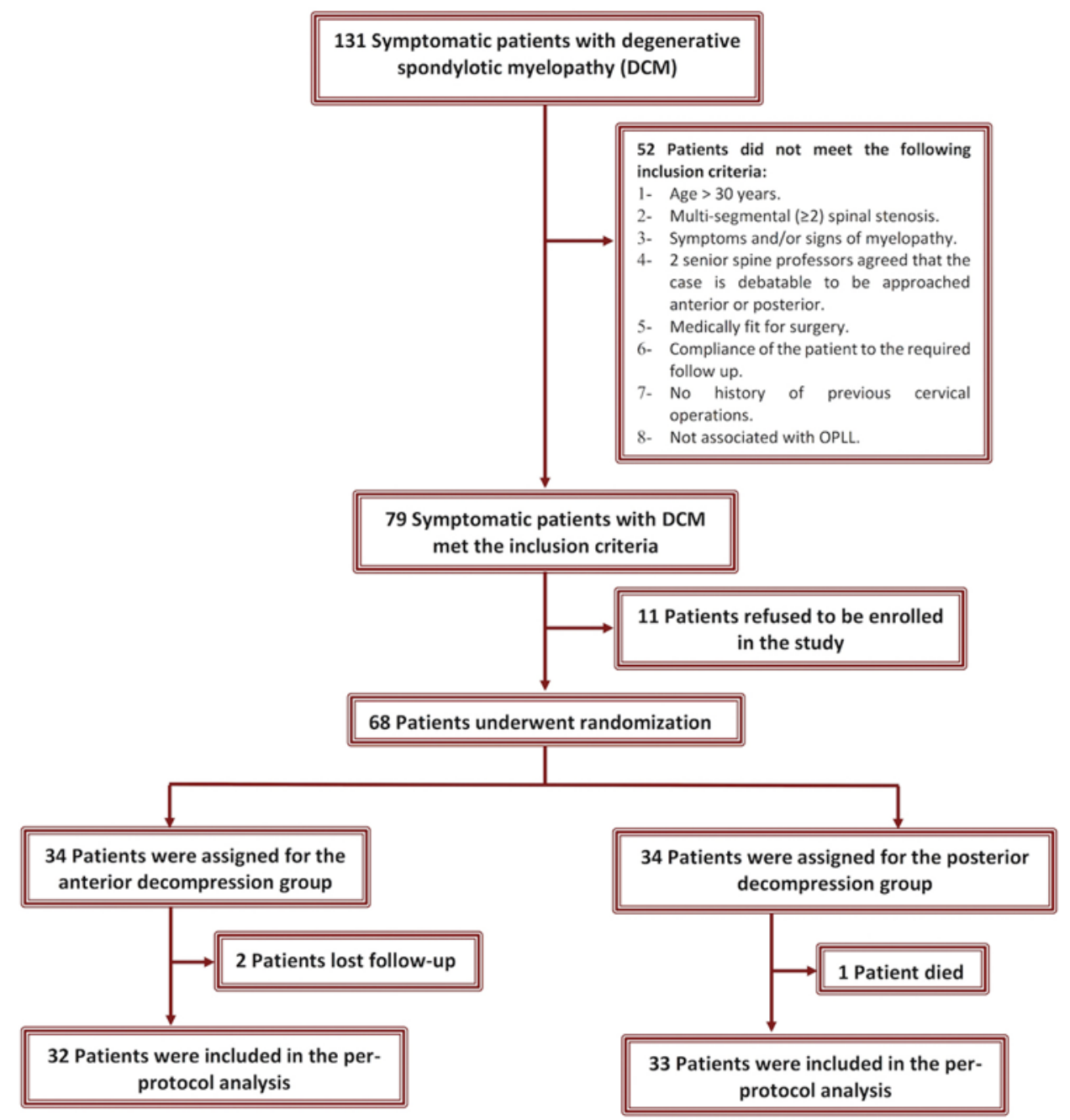

FIG. 1. Flowchart showing the enrollment, randomization, treatment, and 1-year follow-up. Figure is available in color online only.

of the neurosurgery department of Cairo University, and all enrolled patients signed written informed consent. The trial was conducted in accordance with the protocol.

\section{Statistical Analysis}

We estimated the sample size based on the prospective study that was performed by Kadanka et al. in 2002 and Ghogawala et al. in 2011.,8 The NDI was used as the primary outcome endpoint. Based on the observed means and standard deviations in our sample, the post hoc analysis revealed that the observed effect size was large (Cohen's $d=0.65$ ). The observed power using a 2-tailed alpha of 0.05 and an equally divided sample of 68 participants was 0.75 . Our analysis included randomized patients who completed the 1-year follow-up. The baseline demographics (age, sex ratio, and levels involved), clinical characteristics (preoperative NDI score, VAS score, and Nurick myelopathy grade), and clinical outcomes (postoperative complications; postoperative NDI, VAS, and Nurick myelopathy grade; and patient satisfaction) were evaluated using descriptive statistics. Continuous variables were presented in the form of means \pm standard deviations and compared using independent t-tests. The categorical variables were presented in the form of numbers and percentages and were compared using Fisher's exact or chi-square tests. We analyzed the variations over a period of time using the paired Student t-test. The statistical significance was set at $\mathrm{p}<0.05$.

\section{Results}

\section{Patients}

From January 2017 through June 2018, a total of 68 patients were enrolled in the study (Fig. 1), with a mean age of $53 \pm 8.3$ years. There were no significant differences in the patient demographics, general health, and baseline characteristics between the treatment groups (Table 2). A total of 34 patients were assigned to the anterior decompression group, and 2 of those patients were lost to follow-up; 34 patients were assigned to the posterior decompression group, and 1 of those patients died during the first year after surgery from myocardial infarction. Therefore, the per-protocol analysis included 65 patients: 32 in the ACDF group and 33 in the posterior decompression group (26 laminectomies and 7 laminectomies with lateral mass fusion). 
TABLE 2. Patient demographics

\begin{tabular}{|c|c|c|c|}
\hline Parameter & $\begin{array}{c}\text { Anterior } \\
\text { Decompression (\%) }\end{array}$ & $\begin{array}{c}\text { Posterior } \\
\text { Decompression (\%) }\end{array}$ & $p$ Value \\
\hline No. of patients & 32 & $33^{*}$ & \\
\hline Mean age, yrs & $52.7 \pm 6.7$ & $53.4 \pm 9.6$ & 0.73 \\
\hline Male sex & $22(68.8)$ & $25(75.8)$ & 0.53 \\
\hline \multicolumn{4}{|l|}{ No. of comorbidities } \\
\hline Diabetes & 9 & 8 & 0.72 \\
\hline Hypertension & 4 & 5 & 0.76 \\
\hline Hepatic & 4 & 2 & 0.37 \\
\hline Rheumatoid arthritis & 0 & 1 & 0.32 \\
\hline Smokers & 15 & 11 & 0.27 \\
\hline \multicolumn{4}{|l|}{ No. of levels involved } \\
\hline 2 & $8(25)$ & $9(27.3)$ & 0.83 \\
\hline 3 & $16(50)$ & $12(36.4)$ & 0.27 \\
\hline 4 & $7(21.9)$ & $9(27.3)$ & 0.61 \\
\hline 5 & $1(3.1)$ & $3(9.1)$ & 0.32 \\
\hline $\begin{array}{l}\text { No. of patients w/ kyphosis, loss of lordosis, or } \\
\text { signs of instability }\end{array}$ & 9 & 7 & 0.52 \\
\hline \multicolumn{4}{|l|}{ Presenting symptoms } \\
\hline Neck pain & $25(78.1)$ & $24(72.7)$ & 0.61 \\
\hline Radiculopathy & $19(59.4)$ & $14(42.4)$ & 0.17 \\
\hline Myelopathy & $23(71.9)$ & $26(78.8)$ & 0.52 \\
\hline Bladder dysfunction & $13(40.6)$ & $14(42.4)$ & 0.88 \\
\hline Weakness & $30(93.8)$ & $29(87.9)$ & 0.41 \\
\hline Sensory deficit & $16(50)$ & $17(51.5)$ & 0.9 \\
\hline Spasticity & $14(43.8)$ & $19(57.6)$ & 0.26 \\
\hline Hyperreflexia & $26(81.3)$ & $28(84.8)$ & 0.7 \\
\hline Babinski sign & $24(75)$ & $23(69.7)$ & 0.63 \\
\hline Hoffman sign & $9(28.1)$ & $7(21.2)$ & 0.52 \\
\hline Clonus & $19(59.4)$ & $20(60.6)$ & 0.92 \\
\hline Mean preop pain (VAS) & $5 \pm 2.6$ & $4.3 \pm 2.1$ & 0.24 \\
\hline Mean preop disability (NDI) & $27.2 \pm 9.1$ & $28.2 \pm 9.3$ & 0.69 \\
\hline Mean preop Nurick grade & $2.8 \pm 0.9$ & $2.8 \pm 1$ & $>0.99$ \\
\hline
\end{tabular}

\section{Primary Outcome Measures}

At 1 year after surgery, there was no significant difference between the two treatment groups in the Nurick myelopathy grade; the mean Nurick myelopathy grade at 1 year was $2.13 \pm 0.96$ in the anterior decompression group and $2.06 \pm 1.10$ in the posterior decompression group $(\mathrm{p}=$ 0.79 ; Table 3). The Nurick grade had improved from baseline by $0.63 \pm 0.96$ in the anterior decompression group and by $0.79 \pm 1.09$ in the posterior decompression group $(\mathrm{p}=0.53)$. However, the VAS score and NDI were significantly better in the anterior decompression group at 1 year. The mean VAS score at 1 year after surgery was 2.6 \pm 1.7 in the anterior decompression group and $3.7 \pm 2.1$ in the posterior decompression group ( $<<0.05)$. The VAS score had improved from baseline by $2.4 \pm 2.6$ in the ante- rior decompression group and by $0.6 \pm 2.4$ in the posterior decompression group $(\mathrm{p}<0.05)$. The mean NDI at 1 year after surgery was $13.6 \pm 5.7$ in the anterior decompression group and $17.5 \pm 6.3$ in the posterior decompression group $(\mathrm{p}<0.05)$. The NDI had improved from baseline by $13.8 \pm$ 8.3 in the anterior decompression group and by $10.8 \pm 7.2$ in the posterior decompression group ( $p=0.13$; Fig. 2$)$ On subgroup analysis, we found the same results comparing the anterior and posterior fusion groups in terms of mean improvement from baseline in Nurick myelopathy grade $(\mathrm{p}=0.45)$, VAS score $(\mathrm{p}<0.05)$, and NDI $(\mathrm{p}=0.12)$. Also, in the subgroup analysis of the posterior decompression group, no significant differences were found in the mean improvement from baseline on the Nurick myelopathy grade, VAS score, and NDI between the cervical lami- 
TABLE 3. Patient outcomes

\begin{tabular}{lccc}
\hline \multicolumn{1}{c}{ Parameter } & $\begin{array}{c}\text { Anterior } \\
\text { Decompression (\%) }\end{array}$ & $\begin{array}{c}\text { Posterior } \\
\text { Decompression (\%) }\end{array}$ & p Value \\
\hline Postop complications & & & \\
\hline Dysphagia & $5(15.6)$ & $0(0)$ & $<0.05$ \\
\hline Laryngeal nerve palsy & $2(6.3)$ & $0(0)$ & 0.14 \\
\hline Transient C5 palsy & $1(3.1)$ & $3(9.1)$ & 0.32 \\
\hline Transient weakness & $2(6.3)$ & $3(9.1)$ & 0.67 \\
\hline Superficial wound infection & $0(0)$ & $3(9.1)$ & 0.08 \\
\hline Dural tear & $0(0)$ & $2(6.1)$ & 0.16 \\
\hline Deep infection & $0(0)$ & $1(3)$ & 0.32 \\
\hline Hematoma & $0(0)$ & $0(0)$ & $>0.99$ \\
\hline Vascular injury & $0(0)$ & $0(0)$ & $>0.99$ \\
\hline Mortality & $0(0)$ & $0(0)$ & $>0.99$ \\
\hline Postop mean pain score (VAS) at 1-yr FU & $2.6 \pm 1.7$ & $3.7 \pm 2.1$ & $<0.05$ \\
\hline Postop mean disability score (NDI) at 1-yr FU & $13.6 \pm 5.7$ & $17.5 \pm 6.3$ & $<0.05$ \\
\hline Postop mean Nurick grade at 1-yr FU & $2.13 \pm 0.96$ & $2.06 \pm 1.10$ & 0.79 \\
\hline Odom's criteria & & & \\
\hline Excellent & $5(15.6)$ & $3(9.1)$ & 0.42 \\
\hline Good & $15(46.9)$ & $15(45.5)$ & $>0.99$ \\
\hline Fair & $8(25)$ & $10(30.3)$ & 0.63 \\
\hline Poor & $4(12.5)$ & $5(15.2)$ & 0.76 \\
\hline Mean hospital length of stay, days & $3.5 \pm 1.4$ & $5.2 \pm 2.4$ & $<0.001$ \\
\hline Mean operative duration/level, mins & $62.7 \pm 9.2$ & $33.5 \pm 6.8$ & $<0.001$ \\
\hline FU = follow-up. & & & \\
Values are presented as the number of patients (\%) unless indicated otherwise. Mean values are reported as the mean \\
\pm SD. Boldface type indicates statistical significance. & & & \\
\hline
\end{tabular}

nectomy group and the cervical laminectomy and lateral mass fusion group ( $\mathrm{p}>0.05$; Table 4$)$.

\section{Secondary Outcome Measures}

There was no significant difference in the complication rate between the groups other than dysphagia, which was significantly higher in the anterior decompression group $(\mathrm{p}<0.05)$. Dysphagia occurred in 5 patients $(15.6 \%)$ in the anterior group and none in the posterior group. Hoarseness of voice occurred in 2 patients $(6.3 \%)$ in the anterior group and none in the posterior group. A transient C5 palsy occurred in 3 patients $(9.1 \%)$ in the posterior group and in 1 patient (3.1\%) in the anterior group. A transient motor deficit was found in 3 patients $(9.1 \%)$ in the posterior group and in 2 patients $(6.3 \%)$ in the anterior group. Failure of fusion occurred in 4 patients (12.5\%) in the anterior group (none required further surgery) and in none of the posterior group. Three patients $(9.1 \%)$ with superficial wound infections treated with antibiotics only and 1 patient (3\%) with deep wound infection treated with debridement and antibiotics occurred in the posterior group, and none in the anterior group. Dural tears occurred in 2 patients $(6.1 \%)$ of the posterior decompression group and none in the anterior group. None of the patients had vertebral artery injury, nerve or spinal cord injury, postoperative hematoma, or perioperative mortality (Table 3). According to Odom's criteria for clinical outcome, $62.5 \%$ of the anterior decompression group had excellent or good outcomes compared to $54.5 \%$ in the posterior decompression group $(\mathrm{p}=0.52)$. The mean operative duration per level was significantly longer in the anterior group (62.7 \pm 9.2 minutes) compared to the posterior group $(33.5 \pm 6.8$ minutes; $\mathrm{p}<0.001)$. Finally, the mean hospital length of stay was significantly longer in the posterior group (5.2 \pm 2.4 days) compared to the anterior group $(3.5 \pm 1.4$ days; $p<0.001 ;$ Fig. 2$)$.

\section{Discussion}

DCM is the most common cause of myelopathy in adults over 55 years old, causing progressive disability and impairing the quality of life. Many retrospective studies, systematic reviews, and meta-analyses have attempted to evaluate and compare the safety and effectiveness of anterior versus posterior approaches for decompression of multilevel DCM, aiming to determine which approach is more superior. ${ }^{4,5}$ Unfortunately, given the heterogenicity of complications and outcome reporting and the paucity of well-designed studies, it is impossible to define a superior approach. The safety and efficacy of anterior and posterior decompression surgery in DCM have not been validated in any prospective randomized trial.

The comparative safety and efficacy of anterior versus posterior decompression in DCM was the issue examined 


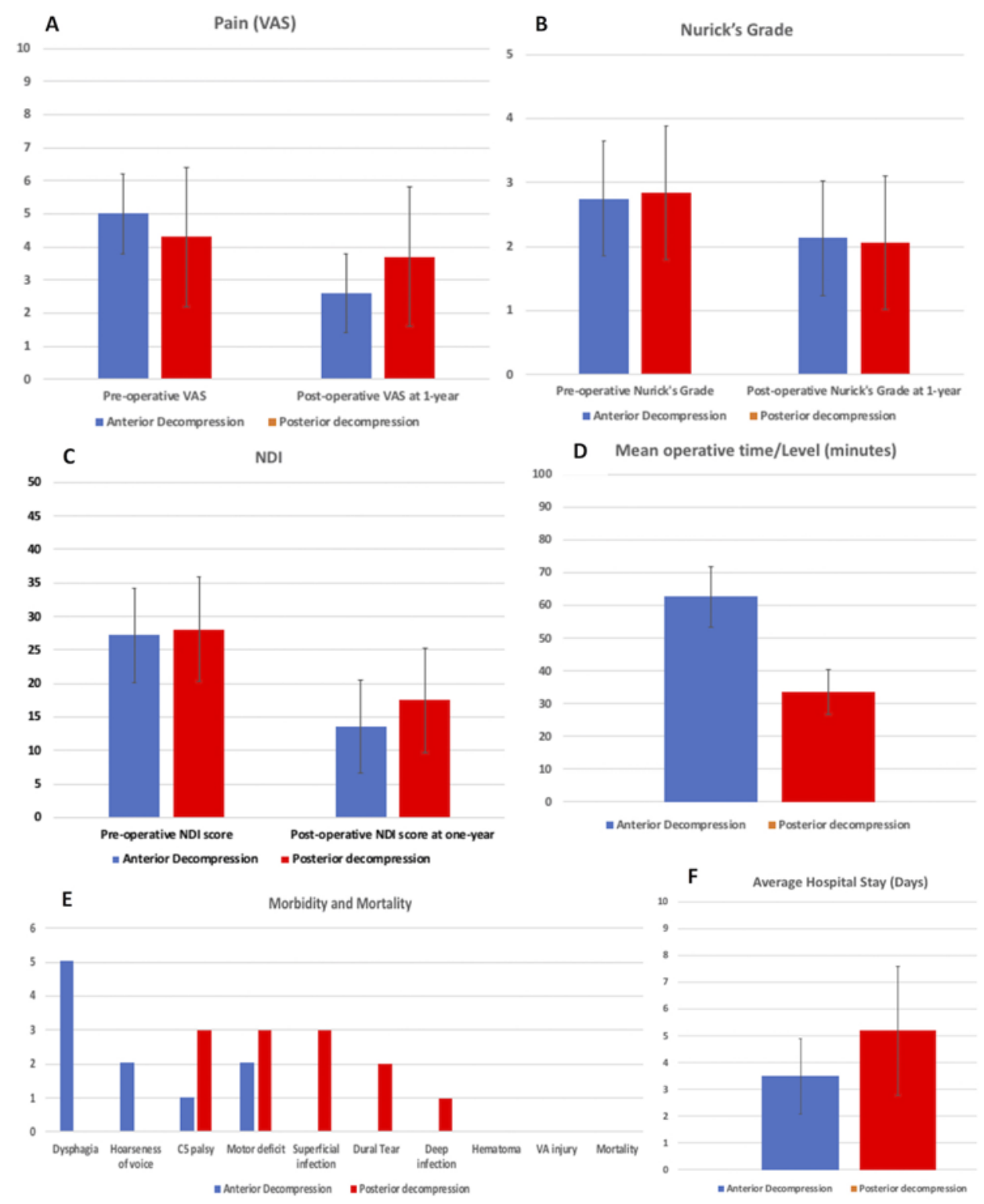

FIG. 2. Bar graphs depicting mean preoperative and 1-year postoperative neck pain scores (A; VAS), Nurick grades (B), and disability (NDI) scores (C) in each treatment group, as well as mean operative duration per level (D), number of complications (E), and hospital length of stay $(\mathbf{F})$. Figure is available in color online only.

in this study, which screened 131 patients for eligibility: 79 patients were enrolled, and 68 patients were randomly assigned. The primary outcome measures were NDI, VAS score, and Nurick myelopathy grade at 1 year. The 1-year follow-up period is similar to the previously published prospective nonrandomized trials by Fehlings et al. and Ghogawala et al., ${ }^{79}$ Although the Nurick myelopathy grade did not differ significantly between the treatment groups at 1 year after surgery, the anterior approach was associated with significantly better scores on the VAS and NDI at 1 year after surgery. Regarding the secondary outcome measures, the intra- and postoperative complications did not differ significantly between the two groups, except the rate of subjective complaint of dysphagia was significantly higher in the anterior group. Concerning the mean operative duration per level, it was significantly higher in the anterior group as well; however, the mean hospital length of stay was significantly higher in the posterior group.

Although 4- or 5-level ACDF is generally not accepted by many spine surgeons, these approaches are performed in our center whenever it is feasible. There are many studies that have reported good outcomes with such surgeries. ${ }^{10-14}$ In this study, if a long-segment anterior approach was not feasible, the patient was excluded from randomization. Furthermore, despite the fact that $25 \%$ of the anterior group patients underwent $\geq 4$-level ACDF, the clinical outcomes were better than in the posterior group.

There is a lot of controversy regarding the long-term 
TABLE 4. Subgroup analysis of primary outcomes of the posterior group

\begin{tabular}{lccr}
\hline \multicolumn{1}{c}{ Parameter } & $\begin{array}{c}\text { Cervical Laminectomy } \\
(\mathrm{n}=26)\end{array}$ & $\begin{array}{c}\text { Cervical Laminectomy \& Lateral } \\
\text { Mass Fusion }(\mathrm{n}=7)\end{array}$ & p Value \\
\hline Mean preop pain (VAS) & $4.1 \pm 2.1$ & $5.1 \pm 1.8$ & 0.23 \\
\hline Mean postop pain (VAS) & $3.3 \pm 2$ & $5 \pm 1.9$ & 0.07 \\
\hline Change in mean pain (VAS) & $0.8 \pm 2.6$ & $0.1 \pm 0.8$ & 0.25 \\
\hline Mean preop disability (NDI) & $26.8 \pm 10$ & $33.3 \pm 2.3$ & $<0.05$ \\
\hline Mean postop disability (NDI) & $15.8 \pm 5.4$ & $23.4 \pm 5.9$ & $<0.05$ \\
\hline Change in mean disability (NDI) & $11 \pm 7.7$ & $9.9 \pm 5$ & 0.66 \\
\hline Mean preop Nurick grade & $2.7 \pm 1$ & $3.3 \pm 0.9$ & 0.16 \\
\hline Mean postop Nurick grade & $2 \pm 1.1$ & $2.1 \pm 1.1$ & 0.84 \\
\hline Change in mean Nurick grade & $0.7 \pm 1$ & $1.1 \pm 1.5$ & 0.52 \\
\hline
\end{tabular}

Values are reported as the mean \pm SD. Boldface type indicates statistical significance.

outcomes of cervical laminectomy (especially progressive kyphosis and instability) among spine surgeons. In North America, most surgeons add fusion to the laminectomy procedure, regardless of the preoperative spine stability and curvature, to avoid these complications. ${ }^{15-17}$ However, this is not the case in our center; the decision to fuse or not is made according to the preoperative dynamic radiographic images (e.g., signs of instability, loss of normal cervical lordotic curve, or kyphotic deformity), and during the laminectomy, medial facet resection greater than $25 \%$ is avoided. This concept was adopted in many other studies..$^{18-23}$

\section{Primary Outcome Measures}

In the present study, there was a significant improvement in the Nurick grade in both groups, with no significant difference between either approach $(p=0.79)$. Our results are similar to the results reported by Edwards et al. ${ }^{24}$ and Fehlings et al..9 however, Kristof et al..$^{25}$ reported that there was no significant improvement after surgery in either group using this measure, while Cahueque Lemus et al. observed a significant improvement in both groups but which was significantly better in the anterior group. ${ }^{26}$ Regarding the patient-reported pain score (VAS), an overall significant improvement in neck pain in both groups was observed but was significantly better in the anterior decompression group at 1 year after surgery $(\mathrm{p}<0.05)$. This is not similar to the results reported by Kristof et al., who reported no significant difference in the VAS score between groups. ${ }^{25}$ Finally, we observed an overall significant improvement in the NDI in both groups, which was significantly better in the anterior decompression group. These results were similar to those of Audat et al..$^{27}$ and Ghogawala et al., 7 who showed a significantly better improvement in the anterior group, while Asher et al. ${ }^{28} \mathrm{ob}$ served a nonsignificantly better improvement in the anterior group and Fehlings et al. ${ }^{9}$ observed a nonsignificantly better improvement in the posterior group.

\section{Secondary Outcome Measures}

In the present study, a nonsignificantly better outcome was observed in the anterior decompression group ac- cording to Odom's criteria $(\mathrm{p}=0.52)$. These results are different from those of Cabraja et al., ${ }^{29}$ which showed a nonsignificantly better outcome in the posterior decompression group $(\mathrm{p}=0.71)$. We observed dysphagia only in the anterior approach group (15.6\%), and all cases resolved at the 6-month follow-up (none required a gastric feeding). This rate was nearly similar to that of Ghogawala et al. ${ }^{7}(14.3 \%)$, slightly higher than the rate found by Liu et al. ${ }^{30}(8 \%)$, Asher et al. ${ }^{28}(6.1 \%)$, and Kristof et al..$^{25}(7.1 \%)$, and was lower than the rate reported by Edwards et al. ${ }^{24}$ $(30.8 \%)$. Hoarseness of voice was only observed in the anterior group (6.3\%), which is nearly similar to that reported in the series by Liu et al. ${ }^{30}(8 \%)$ and Kristof et al. ${ }^{25}(7.1 \%)$, higher than in the study by Asher et al. ${ }^{28}(0 \%)$, and lower than the series of Edwards et al. ${ }^{24}(15.6 \%)$. All of the cases with hoarseness of voice resolved within the first week after surgery. Furthermore, we observed a higher rate of transient $\mathrm{C} 5$ palsy in the posterior group (9.1\%) compared to the anterior group (3.1\%), which was similar to the studies of Liu et al..$^{30}$ (7.4\% vs 0\%), Ghogawala et al. ${ }^{7}(13.6 \%$ vs $0 \%$, and Shibuya et al. ${ }^{31}$ (10\% vs 9\%), while Yonenobu et al. ${ }^{32}$ showed a higher rate of C5 palsy in the anterior decompression group (7\% vs $10 \%$ ). The fusion failure rate was only observed in $12.5 \%$ of the anterior decompression group and in none of the posterior group, which is very similar to the rates reported by Benzel et al. ${ }^{33}(11.8 \%$ vs $0 \%$ ), higher than the rates reported by Liu et al. ${ }^{30}$ (4\% vs $0 \%$ ) and Edwards et al..$^{24}(7.7 \%$ vs $0 \%)$, and lower than those of Yonenobu et al. ${ }^{32}$ (83.4\% vs 0\%), Shibuya et al. ${ }^{31}$ (17.6\% vs $0 \%$ ), and Kristof et al..$^{25}(16.6 \%$ vs $6.5 \%)$. The infection rate in our study was $12.1 \%(9.1 \%$ superficial and $3 \%$ deep) in the posterior group and none in the anterior group. Similarly, a higher rate of infection in the posterior group was observed by Kristof et al..$^{25}$ (6.5\% vs $\left.2 \%\right)$, Asher et al. ${ }^{28}$ (1.2\% vs $0.6 \%$ ), and Fehlings et al. ${ }^{9}$ (4.2\% vs $0.6 \%$ ), while Benzel et al..$^{33}$ observed a higher rate of infection in the anterior group ( $0 \%$ vs $5.9 \%$ ). The dural tear rate in our study was $6.1 \%$ in the posterior group and none in the anterior group; Audat et al. ${ }^{27}$ (2.8\% vs 0\%) and Asher et al. ${ }^{28}(1.2 \%$ vs $0 \%)$ also found a higher rate of dural tear in the posterior group. The mean operative duration per level in the present study was significantly longer in the anterior group compared to the posterior group $(\mathrm{p}<0.001)$, which 
is similar to other series..$^{24,25,28,30,31}$ Finally, the mean hospital stay was significantly longer in the posterior group compared to the anterior group ( $\mathrm{p}<0.001)$, which is also similar to other series..$^{7,24,28}$

There were nonsignificant, marginal differences between patients in both groups in the baseline variables. These baseline differences might be attributed to some of the observed outcome differences rather than to the randomized approach. Other studies are required to validate the findings noted in this study.

\section{Study Limitations}

Among the limitations of this study is the lack of computerized randomization of the patients; however, this limitation was addressed by randomization of patients by a person blinded to the study. We did not use the modified Japanese Orthopaedic Association score for assessing myelopathy improvement and were limited only to the Nurick myelopathy grade. There were no laminoplasty patients in our cohort due to the high financial burden on the patients to undergo laminoplasty in our country (the laminoplasty instrumentation was much more expensive at the time of the study). Furthermore, segmental and global sagittal balance measures were not compared in this study. Larger studies with longer follow-up periods are required for proper evaluation of the best method of DCM treatment.

\section{Conclusions}

Surgery for treating DCM from both anterior and posterior approaches was associated with significant improvements in the Nurick myelopathy grade, VAS score, and NDI at 1 year after surgery. Greater improvement in NDI and VAS score at 1 year after surgery and shorter hospital stay was observed in the anterior decompression surgery. Posterior decompression surgery was associated with longer operative duration per level and a lower rate of dysphagia. Therefore, anterior decompression surgery is associated with better functional outcome, but the higher surgery-related complication rate with the anterior approach should be taken into consideration. Further prospective randomized clinical studies with a larger number of patients and longer follow-up duration are required to validate our results.

\section{Acknowledgments}

Special thanks to Prof. Maher El-Masri and Dr. Amany Ahmed for their help with the study statistical analysis.

\section{References}

1. Tracy JA, Bartleson JD. Cervical spondylotic myelopathy. Neurologist. 2010;16(3):176-187.

2. Nouri A, Tetreault L, Singh A, et al. Degenerative cervical myelopathy: epidemiology, genetics, and pathogenesis. Spine (Phila Pa 1976). 2015;40(12):E675-E693.

3. Karadimas SK, Erwin WM, Ely CG, et al. Pathophysiology and natural history of cervical spondylotic myelopathy. Spine (Phila Pa 1976). 2013;38(22)(suppl 1):S21-S36.

4. Lawrence BD, Jacobs WB, Norvell DC, et al. Anterior versus posterior approach for treatment of cervical spondylotic myelopathy: a systematic review. Spine (Phila Pa 1976). 2013;38(22)(suppl 1):S173-S182.
5. McCormick WE, Steinmetz MP, Benzel EC. Cervical spondylotic myelopathy: make the difficult diagnosis, then refer for surgery. Cleve Clin J Med. 2003;70(10):899-904.

6. Epstein NE. Laminectomy for cervical myelopathy. Spinal Cord. 2003;41(6):317-327.

7. Ghogawala Z, Martin B, Benzel EC, et al. Comparative effectiveness of ventral vs dorsal surgery for cervical spondylotic myelopathy. Neurosurgery. 2011;68(3):622-631.

8. Kadanka Z, Mareš M, Bednaník J, et al. Approaches to spondylotic cervical myelopathy: conservative versus surgical results in a 3-year follow-up study. Spine (Phila Pa 1976). 2002;27(20):2205-2211.

9. Fehlings MG, Barry S, Kopjar B, et al. Anterior versus posterior surgical approaches to treat cervical spondylotic myelopathy: outcomes of the prospective multicenter AOSpine North America CSM study in 264 patients. Spine (Phila Pa 1976). 2013;38(26):2247-2252.

10. Houten JK, Weinstein GR, Collins M. Long-term fate of C3-7 arthrodesis: 4-level ACDF versus cervical laminectomy and fusion [published online October 2, 2018]. J Neurosurg Sci. doi:10.23736/S0390-5616.18.04563-0

11. Kim S, Alan N, Sansosti A, et al. Complications after 3- and 4-level anterior cervical diskectomy and fusion. World Neurosurg. 2019;130:e1105-e1110.

12. Koller H, Hempfing A, Ferraris L, et al. 4- and 5-level anterior fusions of the cervical spine: review of literature and clinical results. Eur Spine J. 2007;16(12):2055-2071.

13. Kreitz TM, Hollern DA, Padegimas EM, et al. Clinical outcomes after four-level anterior cervical discectomy and fusion. Global Spine J. 2018;8(8):776-783.

14. Wang S-J, Ma B, Huang Y-F, et al. Four-level anterior cervical discectomy and fusion for cervical spondylotic myelopathy. J Orthop Surg (Hong Kong). 2016;24(3):338-343.

15. Kode S, Kallemeyn NA, Smucker JD, et al. The effect of multi-level laminoplasty and laminectomy on the biomechanics of the cervical spine: a finite element study. Iowa Orthop J. 2014;34:150-157.

16. Kumaresan S, Yoganandan N, Pintar FA, et al. Finite element modeling of cervical laminectomy with graded facetectomy. J Spinal Disord. 1997;10(1):40-46.

17. Subramaniam V, Chamberlain RH, Theodore N, et al. Biomechanical effects of laminoplasty versus laminectomy: stenosis and stability. Spine (Phila Pa 1976). 2009;34(16):E573E578.

18. Kim BS, Dhillon RS. Cervical laminectomy with or without lateral mass instrumentation: a comparison of outcomes. Clin Spine Surg. 2019;32(6):226-232.

19. Laiginhas ARA, Silva PA, Pereira P, Vaz R. Long-term clinical and radiological follow-up after laminectomy for cervical spondylotic myelopathy. Surg Neurol Int. 2015;6:162.

20. Li Z, Xue Y, He D, et al. Extensive laminectomy for multilevel cervical stenosis with ligamentum flavum hypertrophy: more than 10 years follow-up. Eur Spine J. 2015;24(8):16051612.

21. Löfgren H, Osman A, Blomqvist A, Vavruch L. Sagittal alignment after laminectomy without fusion as treatment for cervical spondylotic myelopathy: follow-up of minimum 4 years postoperatively [published online June 26, 2019]. Global Spine J. doi:10.1177/2192568219858302

22. Nurboja B, Kachramanoglou C, Choi D. Cervical laminectomy vs laminoplasty: is there a difference in outcome and postoperative pain? Neurosurgery. 2012;70(4):965-970.

23. van Geest S, de Vormer AMJ, Arts MP, et al. Long-term follow-up of clinical and radiological outcome after cervical laminectomy. Eur Spine J. 2015;24(suppl 2):229-235.

24. Edwards CCI II, Heller JG, Murakami H. Corpectomy versus laminoplasty for multilevel cervical myelopathy: an independent matched-cohort analysis. Spine (Phila Pa 1976). 2002;27(11):1168-1175. 
25. Kristof RA, Kiefer T, Thudium M, et al. Comparison of ventral corpectomy and plate-screw-instrumented fusion with dorsal laminectomy and rod-screw-instrumented fusion for treatment of at least two vertebral-level spondylotic cervical myelopathy. Eur Spine J. 2009;18(12):1951-1956.

26. Cahueque Lemus MA, Cobar Bustamante AE, Ortiz Muciño A, Caldera Hernandez G. Clinical outcome of anterior vs posterior approach for cervical spondylotic myelopathy. $J$ Orthop. 2016;13(3):123-126.

27. Audat ZA, Fawareh MD, Radydeh AM, et al. Anterior versus posterior approach to treat cervical spondylotic myelopathy, clinical and radiological results with long period of followup. SAGE Open Med. 2018;6:2050312118766199.

28. Asher AL, Devin CJ, Kerezoudis P, et al. Comparison of outcomes following anterior vs posterior fusion surgery for patients with degenerative cervical myelopathy: an analysis from Quality Outcomes Database. Neurosurgery. 2019;84(4):919-926.

29. Cabraja M, Abbushi A, Koeppen D, et al. Comparison between anterior and posterior decompression with instrumentation for cervical spondylotic myelopathy: sagittal alignment and clinical outcome. Neurosurg Focus. 2010;28(3):E15.

30. Liu T, Yang H-L, Xu Y-Z, et al. ACDF with the PCB cageplate system versus laminoplasty for multilevel cervical spondylotic myelopathy. J Spinal Disord Tech . 2011;24(4):213220.

31. Shibuya S, Komatsubara S, Oka S, et al. Differences between subtotal corpectomy and laminoplasty for cervical spondylotic myelopathy. Spinal Cord. 2010;48(3):214-220.

32. Yonenobu K, Hosono N, Iwasaki M, et al. Laminoplasty versus subtotal corpectomy. A comparative study of results in multisegmental cervical spondylotic myelopathy. Spine (Phila Pa 1976). 1992;17(11):1281-1284.
33. Benzel EC, Lancon J, Kesterson L, Hadden T. Cervical laminectomy and dentate ligament section for cervical spondylotic myelopathy. J Spinal Disord. 1991;4(3):286-295.

\section{Disclosures}

The authors report no conflict of interest concerning the materials or methods used in this study or the findings specified in this paper.

\section{Author Contributions}

Conception and design: El-Ghandour, Soliman, Ezzat, ZeinElabedin. Acquisition of data: Ezzat. Analysis and interpretation of data: Soliman, Mohsen. Drafting the article: Soliman. Critically revising the article: all authors. Reviewed submitted version of manuscript: all authors. Approved the final version of the manuscript on behalf of all authors: Soliman. Statistical analysis: Soliman. Administrative/technical/material support: El-Ghandour, Ezzat. Study supervision: El-Ghandour, Mohsen, Zein-Elabedin.

\section{Supplemental Information}

\section{Previous Presentations}

This study was given as an oral presentation (late-breaking abstract) at the CNS Annual Meeting on October 21, 2019, in San Francisco, California.

\section{Correspondence}

Mohamed A. R. Soliman: Cairo University, Cairo, Egypt. moh.ar.sol@kasralainy.edu.eg. 